\title{
In Vitro Characterization of HIV Type 1 Biological Clones from Asymptomatic and Symptomatic Pediatric Patients
}

\author{
SERENE E. FORTE, JOHN L. SULLIVAN, and MOHAN SOMASUNDARAN
}

\begin{abstract}
To investigate the mechanisms of HIV-1 cytopathogenicity, functional biological HIV-1 clones were isolated from two infected children with high viral loads in vivo. Clone HC4 was isolated from a symptomatic child and clone GC6 8-4 was isolated from an asymptomatic child. These clones were characterized for their ability to induce syncytia, and to replicate and induce single-cell death in peripheral blood-derived normal CD4 $T$ cell cultures containing anti-CD4 antibody. Despite similar viral loads as determined by p24 antigen production or viral RNA expression, GC6 8-4 was noncytopathogenic and HC4 was cytopathogenic. Since we had demonstrated that mitochondrial dysfunction correlated with HIV-1-induced cell death, we determined whether the cytopathogenic HC4 clone decreased mitochondrial viability using a mitochondrial-specific dye, rhodamine-123. Following infection, mitochondrial viability decreased in cells infected with HC4 by day 4 and continued to decline through day 7 when compared to uninfected cells. By day 7 postinfection, greater than $80 \%$ of the cells in culture were dead. Similar analyses on CD4 T cells infected with the noncytopathogenic GC6 8-4 demonstrated that mitochondria remained functionally viable and $>90 \%$ of the cells excluded trypan blue. These studies describe a cell culture system to study single-cell death in the absence of syncytia and secondary infection. Results with two patient-derived HIV-1 biological clones suggest that loss of mitochondrial viability may play a role in HIV-1-induced cytopathogenicity.
\end{abstract}

\section{INTRODUCTION}

$\mathbf{H}$ UMAN IMMUNODEFICIENCY VIRUS TYPE 1-induced cytopathogenicity leads to a quantitative depletion of and abnormal function of CD4 T cells in vivo and is a major factor contributing to the immunosuppression associated with HIV-1 infection. ${ }^{1,2}$ The mechanism of in vivo HIV-1-induced cytopathic effects that contribute to the dramatic loss of CD4 T cells remains unknown. In addition to high viral load usurping the host cell synthetic machinery, ${ }^{3}$ proposed mechanisms of cytopathogenicity include syncytium formation, ${ }^{4}$ intracellular HIV-1 gp 160/120-CD4 complexing, ${ }^{5}$ accumulation of unintegrated viral DNA, ${ }^{6}$ viral-induced apoptosis, ${ }^{7}$ and viral-induced mitochondrial toxicity. ${ }^{8}$ These studies suggest a cause-and-effect relationship between the viral life cycle and cytopathic effects.

Earlier reports have suggested an association between high viral burden and HIV-1-induced CD4 T cell attrition in vivo. ${ }^{9,10}$ Reports have correlated rapid decline of CD4 $\mathrm{T}$ cells in vivo with high levels of peripheral viremia. ${ }^{11,12}$ However, we have observed rare individuals with high viral load who maintain normal numbers of CD4 T cells for prolonged periods of time. This suggested to us that the two processes of viral replication and viral induced cytopathogenicity can be segregated and that high levels of viral replication can be maintained without causing cell death. We hypothesize that the low cytopathogenic potential of the virus may be responsible for certain infected individuals with high viral burdens remaining well with an intact immune system.

In the present study, we describe the biological characterization of HIV-1 isolates from two seropositive, pediatric individuals. Functional biological clones of the primary isolates were obtained by limiting dilution culture. The syncytium-inducing (SI) and non-syncytium-inducing (NSI) phenotype in MT-2 cells, and the replication characteristics and cytopathogenic potential in normal peripheral blood CD4 T cells, were analyzed. One biological clone isolated from a symptomatic child with AIDS induced cell death in the absence of syncytium formation. In contrast, another HIV-1 clone isolated from an asymptomatic individual was noncytopathogenic. We have pre-

Department of Pediatrics and Program in Molecular Medicine, University of Massachusetts Medical Center, Worcester, Massachusetts 01605. 
viously reported that decreases in mitochondrial viability play a role in $\mathrm{T}$ cell death induced by cytopathogenic laboratory isolates of HIV-1. ${ }^{8}$ Data supporting a possible role for mitochondria in cell death induced by patient biological clones in vitro are presented in this article.

\section{MATERIALS AND METHODS}

\section{Patients}

Patient A was clinically asymptomatic and was N1 according to the Centers for Disease Control (CDC, Atlanta, GA) classification of disease stage. At the time of viral isolation, patient A was 47 months old, with normal CD4 counts of $2312 / \mathrm{mm}^{3}$. Unexpectedly, peripheral viremia in this child was very high as determined by serum HIV-1 p24 antigen levels (1773 pg/ml) and plasma viral RNA copies $(280,000 / \mathrm{ml})$. Since the original viral isolate was obtained patient $\mathrm{A}$ has maintained normal CD4 $T$ cell numbers, and p24 antigen levels along with plasma viral RNA levels have remained elevated. Patient D had AIDS at the time of viral isolation and was B3 according to the CDC classification of disease stage. The child was 36 months old with very low CD4 $\mathrm{T}$ cell counts $\left(64 / \mathrm{mm}^{3}\right)$.

\section{Isolation and titration of viruses}

HIV-1 was isolated from the infected children described above by coculture with phytohemagglutinin (PHA)-stimulated normal seronegative donor peripheral blood mononuclear cells (PBMCs) according to the AIDS Clinical Trial Group (ACTG) VRL protocol. ${ }^{13}$ Viral isolates from patients $A$ and $D$ were titered using standard methods on PHA-stimulated normal seronegative donor PBMCs. ${ }^{14}$

\section{Biological cloning}

Biological clones of HIV-1 were obtained from the viral isolates of patients $A$ and $D$ according to a modified procedure described earlier by Connor et al. ${ }^{15}$ Briefly, PHA-stimulated seronegative donor PBMCs were infected with primary isolates obtained from patient $A$ at $\mathbf{4 7}$ months of age and from patient $\mathrm{D}$ at 36 months of age. These cell cultures were monitored for cell-free HIV-1 p24 antigen on days 4 and 7 postinfection. When p24 levels exceeded $30 \mathrm{pg} / \mathrm{ml}$, the infected cells were diluted in a 4-fold series and seeded in 96-well plates in replicates of 10 containing from 1000 to 0.24 cells/well. Infected cells were cocultured with $1 \times 10^{6}$ PHA-stimulated seronegative donor PBMCs per well. Cultures were monitored for cellfree HIV-1 p24 antigen on days 7 and 11 postcoculture. A culture was considered positive if the p24 values was $\geq 30 \mathrm{pg} / \mathrm{ml}$. HIV-1 from wells seeded with less than one infected cell per well was propagated in a single short-term coculture (5-7 days) with PHA-stimulated seronegative donor PBMCs and was titered on seronegative PBMCs to determine the $50 \%$ tissue culture infectious dose $\left(\mathrm{TCID}_{50}\right)$.

\section{Determination of clonality}

Clonality of the putative biological clones was assessed by analyzing the nucleotide sequences within the V3 domain of the HIV-1 env gene obtained from cell lysates of PBMCs in- fected with each of the putative biological clones. Amplification by polymerase chain reaction (PCR) and direct sequencing of the V3 domain were carried out by previously described methods. ${ }^{15}$ Briefly, sequences containing the V3 region of HIV-1 $e n v$ were amplified by PCR, using the following primers: $\mathrm{V}^{+} 0^{+}$ (5' TACAATGTACACATGGAATT, position 6535-6554 of HXB2) and $\mathrm{V}^{-} 0^{-}$(5' ATTACAGTAGAAAAATTCCCC, position 6959-6939 of HXB2). ${ }^{15-18}$ The PCR products from these reactions were subjected to a second round of asymmetric PCR, using a single internal primer: either PCR-1(+) (5' GCTAAAACCATAATAGTACAGCTG, position 6642-6665) or PCR2(-) (5' CAATTTCTGGGTCCCCTCCTGAGG, position 6915-6892). ${ }^{15-18}$ The resulting single-stranded products were then directly sequenced, using the Sequenase version 2.0 kit (United States Biochemicals, Cleveland, $\mathrm{OH}$ ). Multiple biological clones were isolated from each of the primary isolates of patient A and patient D. Further characterization of HIV-1 cytopathogenicity and the role of mitochondria were determined using a single clone from patient A (GC6 8-4) and from patient D (HC4).

\section{In vitro characterization of syncytium-inducing viral phenotype}

The syncytium-inducing (SI) and non-syncytium-inducing (NSI) phenotype of HIV-1 biological clones were determined in MT-2 cells, using the standardized protocol formulated by the ACTG Virology Committee. ${ }^{19,20}$ Titered stocks of HIV-1 clones $(50 \mu \mathrm{l})$ were used to infect quadruplicate microcultures of MT- 2 cells $\left(5 \times 10^{4}\right)$ in wells of 96-well tissue culture plates containing $200-\mu$ l final volume. Positive controls were set up using titered stocks of HIV-1 NL4-3 (TCID $_{50} / 50 \mu \mathrm{l}=32,750$ ). Negative controls were either RPMI 1640 medium containing $10 \%$ fetal calf serum (FCS), or $8 E 5$ cell culture supernatant containing a pol-defective, noninfectious NL4-3 HIV-1 strain. ${ }^{21}$ Plates were incubated at $37^{\circ} \mathrm{C}\left(5 \% \mathrm{CO}_{2}\right)$. Every third day the wells were examined for syncytia, the cell suspension in each well mixed, and $130 \mu l$ of the cell suspension discarded and replaced with $150 \mu \mathrm{l}$ of fresh medium. On day 14 the NSI/SI phenotype of each biological HIV-1 clone was recorded and the assay was terminated. If three to five "balloons" or giant cells were detected per well under high power field, the cell culture was scored as positive for syncytia and the phenotype of the biological viral clone was recorded as SI. An HIV-1 clone that did not induce syncytia in MT-2 cells was phenotyped as NSI.

\section{Infection of PBMCs with biological clones of patient HIV-1 isolates}

Normal PBMCs from HIV-1-seronegative donors were PHA stimulated for 3 days and infected with HIV-1 biological clones, GC6 8-4 and HC4, according to previously described methods. ${ }^{3,22} \mathrm{HIV}-1$-infected and uninfected PBMCs were cultured at $1 \times 10^{6}$ cells/ml in RPMI 1640 supplemented with $10 \%$ fetal calf serum (FCS) and 10 units of recombinant human interleukin 2 (Boehringer-Mannheim, Indianapolis, IN) per milliliter.

\section{Enrichment of CD4 T cells}

PBMCs were isolated using the Ficoll gradient technique and CD4 $T$ cells were negatively enriched using anti-CD8 antibody- 
coated magnetic beads (Dynal, Inc., Lake Success, NY) according to the manufacturer's methodology. Briefly, the beads (10 beads/cell) were washed three times with phosphatebuffered saline (PBS) containing 1\% FCS (PBS-1\% FCS). During each wash, the beads were collected using a magnetic separator. After the final wash, the beads were resuspended in $100 \mu \mathrm{l}$ of ice-cold PBS- $1 \%$ FCS. PBMCs $\left(10^{8}\right.$ cells) were washed once with PBS-1\% FCS, resuspended in $1 \mathrm{ml}$ of icecold PBS-1\% FCS and added to the bead suspension. The mixture was incubated on ice for $20 \mathrm{~min}$ with gentle agitation. The tube was placed upright in a magnetic separator for $5 \mathrm{~min}$ and the supernatant was collected. The beads were washed twice with PBS- $1 \%$ FCS and the supernatants were saved. The supernatants containing CD4 T cells were spun and the cell pellet was resuspended in RPMI 1640 containing 10\% FCS and interleukin 2 (10 units/ml).

\section{Infection of CD4 T cells with biological HIV-1 clones}

CD4 T cells were PHA stimulated overnight and infected with HIV-1 biological clones according to previously described methods. ${ }^{3,22}$ To determine whether the interaction of viral gp120 envelope protein and CD4 antigen was responsible for intracellular events leading to cell death, CD4 T cells were also infected with cell-free supernatant obtained from cultures of chronic, replication-incompetent HIV-1 producers, 8E5 cells. These mock-infected CD4 T cells served as controls for infection experiments. HIV-1-infected and uninfected CD4 T cells were cultured at $1 \times 10^{6}$ cells/ml in RPMI 1640 supplemented with $10 \%$ FCS and recombinant human interleukin 2 (10 units/ml; Boehringer-Mannheim) in the continuous presence of azide-free anti-CD4 antibody at $100 \mathrm{ng} / \mathrm{ml}$ (Biosource International, Camarillo, CA). The anti-CD4 antibody was targeted to the epitope on CD4 antigen that binds to HIV-1 gp 120 envelope. This antibody prevented syncytium formation and blocked secondary infections and, therefore, modified the culture conditions to study single cell death induced by HIV-1.

\section{Assay for HIV-1-induced cytopathogenic effects}

HIV-1-induced cytopathogenic effects of GC68-4 and HC-4 viral clones were determined by evaluating cell viability using the method of trypan blue dye exclusion. Biological clones were determined to be noncytopathogenic (NCP) or cytopathogenic (CP) on the basis of the viability of infected cells.

\section{Determination of $\mathrm{CD}^{+}$and $\mathrm{CD} 8^{+} \mathrm{T}$ cell populations in infected cultures}

Cells $(\sim 500,000)$ from infected and uninfected $T$ cell cultures were washed with cold PBS- $0.1 \%$ azide and then incubated for $\mathbf{3 0} \mathrm{min}$ on ice with a mixture of fluorescein labeled anti-CD4 monoclonal antibody and phycoerythrin-labeled antiCD8 monoclonal antibody (Becton Dickinson, San Jose, CA). The cells were washed with PBS- $0.1 \%$ azide and then fixed for $10 \mathrm{~min}$ at room temperature with $0.2 \%$ paraformaldehyde. The cells were washed with PBS- $-0.1 \%$ azide and then resuspended in PBS and analyzed on a FACScan flow cytometer (Becton Dickinson). Phycoerythrin- and fluorescein-labeled mouse gammaglobulins were used as negative stains for controls.
Determination of proviral copies: Polymerase chain reaction to detect HIV-I DNA

Polymerase chain reaction was performed on lysates of serially diluted CD4 T cells infected with GC6 8-4 or HC4 HIV1 biological clones, using a Roche Amplicor HIV-1 test kit according to a method described by Saiki $e$ al. $^{23}$ and modified by the manufacturer. A region within the HIV-1 gag gene was amplified using biotinylated SK431/SK462 primer pairs in an automated GeneAmp PCR system 9600 thermocycler (PerkinElmer Cetus, Foster City, CA). The cycling parameters were as follows: 5 cycles of denaturation at $95^{\circ} \mathrm{C}$ for $10 \mathrm{sec}$, annealing at $55^{\circ} \mathrm{C}$ for $10 \mathrm{sec}$, and extension at $72^{\circ} \mathrm{C}$ for $10 \mathrm{sec}$; followed by 30 cycles of denaturation at $90^{\circ} \mathrm{C}$ for $10 \mathrm{sec}$, annealing at $60^{\circ} \mathrm{C}$ for $10 \mathrm{sec}$, and extension at $72^{\circ} \mathrm{C}$ for $10 \mathrm{sec}$; followed by a final extension step at $72^{\circ} \mathrm{C}$ for $5 \mathrm{~min}$. The amplicons were captured onto wells coated with the probe and detected by an enzyme-linked immunosorbent assay (ELISA) using avidinconjugated horseradish peroxidase as a secondary marker.

Determination of viral replication: ELISA to detect HIV-1 p24ag protein

To follow HIV-1 replication in infected PBMCs or CD4 T cell cultures, cell-free culture supernatants were assayed for HIV-1 p248ag protein using an antigen capture ELISA (Coulter Immunology, Hialeah, FL) according to the method described by the manufacturer.

Determination of viral replication: Fluorescent in situ hybridization to detect HIV-I RNA

A sample of infected cells was washed with PBS, air dried on microscope slides, and fixed in $4 \%$ paraformaldehyde for 10 $\mathrm{min}$ at room temperature. The slides were rinsed in PBS and stored in $70 \%$ ethanol. At the time of assay, cells were rehydrated and HIV-1 RNA was detected by in situ hybridization using a cocktail of 50 digoxigenin-labeled synthetic oligonucleotide probes (35-mers) targeted to the entire HIV-1 genome. ${ }^{8,24}$ Briefly, $100 \mathrm{ng}$ of oligonucleotide probes in $30 \%$ formamide- $2 \times$ SSC- $5 \%$ dextran sulfate $-2 \mathrm{mM}$ vanadyl sulfate complex- $1 \%$ bovine serum albumin was hybridized overnight at $37^{\circ} \mathrm{C}$ to HIV-1 RNA in infected cells. After a series of washes at $37^{\circ} \mathrm{C}(2 \times$ SSC $-30 \%$ formamide; $1 \times$ SSC $-30 \%$ formamide; $1 \times$ SSC) the cells were washed with PBS- $0.1 \%$ Triton X-100. FITC-labeled anti-digoxigenin antibody $(0.5 \mu \mathrm{g} / \mathrm{ml})$ was used as the marker to detect the hybridized oligonucleotide probes. The percentage of HIV-1 RNA-positive cells was determined in cultures of cells infected with either GC68-4 or HC4 HIV-1 biological clones.

\section{Determination of mitochondrial viability in cells acutely infected with HIV-1 biological clones}

Mitochondrial viability of CD4 T cells from infected cultures was monitored using a rhodamine-123 dye assay. ${ }^{25}$ Briefly, uninfected and infected cells were washed, resuspended in PBS containing $0.1 \mu \mathrm{M}$ rhodamine-123 dye, and incubated in a $37^{\circ} \mathrm{C}$ incubator with $5 \% \mathrm{CO}_{2}$ for $15 \mathrm{~min}$. The cells were washed and resuspended in PBS and then analyzed by FACScan flow cytometer (Becton Dickinson). The histograms of uninfected, mock-infected, and HIV-1 clone-infected CD4 T cells 
were analyzed using Kolmogorov-Smirnov statistics and overlay plots and summation curves were obtained. ${ }^{26}$ The summation curves of the histograms for infected and uninfected cells represented the probability distribution of the individual histograms. The $D / s(n)$ value for the summation curves indicated the degree of similarity between the two histograms. The further the $D / s(n)$ value is from zero, the more dissimilar the histograms were, indicating that the number of viable mitochondria was different between the two cell cultures.

\section{RESULTS}

\section{Patients and HIV-1 isolates}

The absolute CD4 cell counts of HIV-1-seropositive pediatric patients $A$ and $D$ are 2312 and 64 counts $/ \mathrm{mm}^{3}$, respectively. The biological characterization of HIV-1 isolates from these two patients has been described earlier. ${ }^{27}$ The primary HIV-1 isolate A (obtained from patient $A$ at 47 months of age) and the HIV-1 isolate D (obtained from patient D at 36 months of age) were isolated just prior to initiation of therapy and have been used in studies reported here.

\section{Clonality of patient HIV-1 biological clones}

Multiple biological clones were obtained from HIV-1 isolates A and D. A single strand of DNA, 300 bases long within the $\mathrm{V} 3$ region of the $e n v$ gene, was amplified and sequenced by PCR from cell lysates of PBMCs infected with the biological clones. Nucleotide sequence analysis of the products from four separate PCR and sequencing reactions for each putative clone indicated less than $2 \%$ divergence within the $\mathrm{V} 3$ region $^{15}$ and, thus, confirmed the clonality of each HIV-1 isolate.

\section{Non-syncytium-inducing/syncytium-inducing phenotype} of biological clones

All the biological clones from isolate D were SI and all the biological clones from isolate A were NSI in MT-2 cells (Table

Table 1. Phenotype of Functional Biological Clones IsOlated FROM HIV-1 IsOlates A (NONCYTOPATHOGENIC) AND D (CYTOPATHOGENIC)

\begin{tabular}{lrr}
\hline Clone $^{2}$ & MT-2 & phenotype \\
\hline Viral isolate A (NCP) & & Viral titer $^{\mathrm{b}}$ \\
GC6 8-1 & NSI & 103,158 \\
GC6 8-4 & NSI & 259,678 \\
GC6 9-4 & NSI & 4,061 \\
Viral isolate D (CP) & & \\
HC4 & SI & 64,958 \\
HC5 & SI & 16,242 \\
HC6 & SI & 16,242 \\
HC7 & SI & 6,446 \\
HC8 & SI & 10,232 \\
HC9 & SI & 64,958 \\
HC10 & SI & 6,446 \\
\hline
\end{tabular}

aSI, Syncytium inducing; NSI, nonsyncytium inducing. ${ }^{\mathrm{b}} \mathrm{TCID}_{50} / \mathrm{ml}$.

${ }^{\mathrm{c} B i o l o g i c a l}$ clones selected for further characterization.
1). HIV-1 clones HC4 and GC6 8-4 had the highest titers among the viral clones and were further characterized for their cytopathic effects.

\section{Primary infection of PBMCs with HIV-1 isolates A and $D$}

PHA-stimulated donor PBMCs were infected with patient isolate A or D. The viability of PBMCs infected with HIV-1 isolate $A$ did not decrease and remained comparable to the viability of uninfected cells over a period of 21 days (Fig. 1a). In contrast, there was a steady decline in the percentage of viable cells in cultures of PBMCs infected with isolate D. There was a precipitous drop in viability after the 12 th day postinfection (Fig. 1b). By 21 days, there was $>80 \%$ of dead cells in isolate D-infected culture when compared to $<20 \%$ in uninfected culture. Viral production was determined by measuring the levels of p24 antigen in cell-free supernatant. By day 7 postinfection, the p24 antigen levels were similar $(\sim 40 \mathrm{ng} / \mathrm{ml})$ in cultures of PBMCs infected with either isolate A or isolate D.
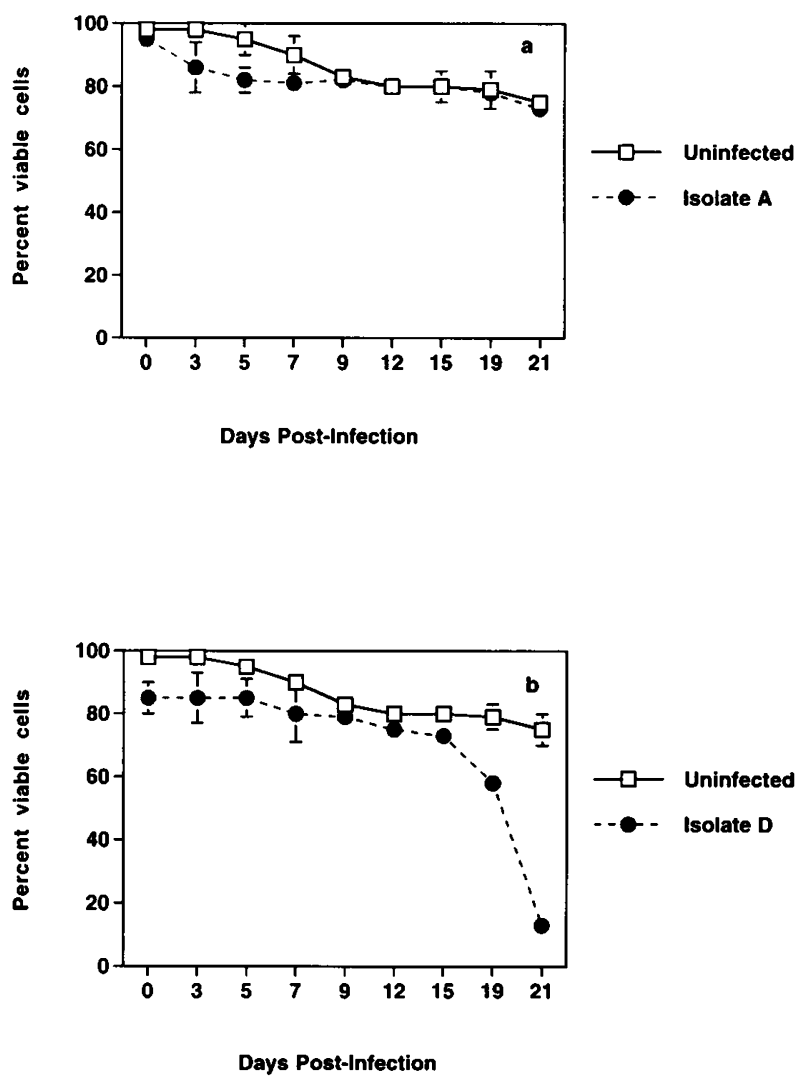

FIG. 1. Viability of peripheral blood mononuclear cells (PBMCs) infected with patient HIV-1 isolates. Mitogen-stimulated PBMCs were infected with titered patient HIV-1 stocks as described in Materials and Methods. Cell death was determined using the trypan blue dye exclusion assay and percent viable cells was calculated. Data from five individual experiments are presented along with standard deviations. (a) PBMCs infected with noncytopathogenic, HIV-1 isolate A; (b) PBMCs infected with cytopathogenic, HIV-1 isolate D. 


\section{Cytopathogenicity of HIV-1 biological clones in PBMCs and CD 4 T cells}

PBMCs were infected with the biological HIV-1 clones HC4 and GC6 8-4. Both viruses replicated to high titers in PBMCs. By day 8 postinfection, p24 antigen levels in cultures infected with GC6 8-4 were $>230 \mathrm{ng} / \mathrm{ml}$, and in cultures infected with HC4 the p24 antigen levels were $>130 \mathrm{ng} / \mathrm{ml}$. However, the two cloned viruses had a much different effect on cell viability. Ten days postinfection with HC4 clone, cell viability had fallen below $50 \%$ compared to the $\sim 80 \%$ viability of uninfected PBMCs. In contrast, 10 days postinfection with GC6 8-4 clone, the cell viability was $75-80 \%$.

The PBMC cultures described above were a mixture of CD4 and CD8 T cells. Since CD8 ${ }^{+} \mathrm{T}$ cells are not susceptible to HIV1 infection and HIV-1-induced cell death, the determination of cell viability in HIV-1-infected PBMC cultures does not truely represent the effects of the virus. Moreover, the clone HC4 has an SI phenotype and can potentially induce syncytia in CD4 T cells. To eliminate the possible contributions of these factors to cell death in infected cultures and to determine the mechanism of single cell lysis by HIV-1, we modified our in vitro culture conditions. Phytohemagglutinin-stimulated, CD4 T cells were used to determine the cytopathogenic potential of HC4 and GC6 8-4 HIV-1 clones. After the initial exposure to the virus, the cells were washed and then cultured in the presence of anti-CD4 antibody to inhibit syncytium formation. Comparable levels of HIV-1 expression in CD4 T cells were observed with both viruses as shown in Table 2. In situ hybridization analysis to detect viral RNA expression revealed that by day 7 postinfection, the percentage of HIV RNA-positive cells in HC4-infected cultures was 29 and 25\% in GC6 8-4-infected cultures (Table 2). Quantitative PCR analyses using HIV-1 gag-specific primer pairs suggested that the proviral copy numbers were similar in CD4 $\mathrm{T}$ cell cultures infected with either GC6 8-4 or HC4 HIV-1 clones (1 copy/10 cells). By day 7 postinfection, p24 antigen levels in cul-

TABLE 2. HIV-1 RNA EXPRESSION AND MrTOCHONDRIAL Viability OF $\mathrm{CD}^{+} \mathrm{T}$ CELlS INFECTED WITH NONCYTOPATHOGENIC OR CYTOPATHOGENIC HIV-1 Biological Clones

\begin{tabular}{ccc}
\hline $\begin{array}{c}\text { Days } \\
\text { postinfection }\end{array}$ & $\begin{array}{c}\text { Percent } \\
\text { expressing } H I V-1 R N A^{\mathrm{a}}\end{array}$ & $\begin{array}{c}\text { Mitochondrial } \\
\text { viability }\end{array}$ \\
\hline
\end{tabular}

\section{Clone HC4}

$\begin{array}{rcc}3 & \mathrm{NC}^{\mathrm{c}} & \mathrm{ND} \\ 5 & 25.4 & 6.52 \\ 7 & 29.4 & 13.09 \\ 10 & \mathrm{ND} & \mathrm{ND}\end{array}$

\section{Clone GC6 8-4}

\begin{tabular}{rcc}
3 & ND & ND \\
5 & 15.9 & 2.02 \\
7 & 25.3 & 2.28 \\
10 & ND & 5.12 \\
\hline
\end{tabular}

apercent positive cells by in situ hybridization.

${ }^{\mathrm{b}} \mathrm{D} / \mathrm{s}(n)$ value from summation curves.

'ND, Not done. tures infected with GC6 8-4 were $363 \mathrm{ng} / \mathrm{ml}$, and in cultures infected with $\mathrm{HC} 4$ the p24 antigen levels were $342 \mathrm{ng} / \mathrm{ml}$ (Fig. 2c). Despite the similar viral load observed in the two infected cultures, there was a dramatically different effect on single cell lysis. Cell viability in cultures infected with the HIV-1 clone, HC4, showed a dramatic drop between day $5(80 \%)$ and day 7 (45\%) postinfection (Fig. 2a). In contrast, viability of cells in cultures infected with the GC6 $8-4$ clone was $>80 \%$ and remained as viable as the uninfected culture or the mock-infected culture during the period of the experiment (Fig. 2a). Loss of viability in uninfected CD4 $\mathrm{T}$ cell cultures by day 10 was probably due to the lack of additional PHA restimulation that is necessary for CD4 $\mathrm{T}$ cells to continue growth in the absence of $\mathrm{CD}^{+} \mathrm{T}$ cellderived cytokines. The noncytopathic effect of GC6 8-4 and the cytopathic effect of $\mathrm{HC} 4$ were also evident by evaluating cell growth in cultures. Between days 5 and 7 postinfection, the total number of cells in HC4-infected cultures declined from 40 million to 5 million cells and at day 10 there were less than 2 million cells remaining (Fig. 2b). In contrast, the total number of cells in GC6 8-4-infected cultures, mock-infected cultures, or uninfected cultures steadily increased from 50 million cells on day 5 to $>150$ million cells by day 10 postinfection (Fig. $2 b$ ).

The percentage of CD4 T cells in uninfected and HIV-1 biological clone-infected cultures was determined by FACScan flow cytometry (Fig. 3). The percentage of CD4 T cells in the HC4 clone-infected culture dramatically declined over 5 to 8 days postinfection. Between days 3 and 5 postinfection, CD4 T cells declined from 82 to $46 \%$ (lower right quadrant, Fig. $3 \mathrm{c}$ ). By day 7 postinfection, the percentage of CD4 T cells decreased to $13 \%$ and by day 10 there was $<3 \%$ in the culture. In contrast, by day 5 postinfection, there was $\sim 86 \%$ of CD4 T cells in the GC6 8-4-infected culture (Fig. $3 \mathrm{~b}$ ), and $\sim 81 \%$ of CD4 $\mathrm{T}$ cells in the uninfected culture (not shown) or mock-infected culture (Fig. 3a). The cells in the lower left quadrant represent viable $\mathrm{T}$ cells that have downregulated their CD4 antigen expression due to viral infection. On day 7 postinfection, $56 \%$ of $\mathrm{T}$ cells in the GC6 8-4-infected culture expressed CD4 antigen and $31 \%$ of viable $\mathrm{T}$ cells had downregulated their expression of CD4 antigen. Since CD4 antigen expression is not affected in uninfected or mock-infected cells, $\sim 82 \%$ of either culture were CD4 T cells. The total number of CD4 T cells remained steady $(67-80 \%)$ over the period of the experiment (10 days) in uninfected cultures, in mock-infected cultures, or in cultures infected with the GC6 8-4 clone (lower left and right quadrants; Fig. 3a and b). In contrast, the total number of CD4 T cells in HC4-infected culture was only $\sim 30 \%$ by day 7 postinfection, and rapidly decreased to $\sim 15 \%$ by day 10 .

\section{Cytopathogenic patient HIV-1 decreases mitochondrial viability in infected CD4 T cells}

The results described above suggest that $\mathrm{HC} 4$ virus is cytopathogenic to CD4 $\mathrm{T}$ cells in the absence of syncytium formation. Viral replication appeared not to be the major contributing factor since GC6 8-4 virus with similar replication levels was noncytopathogenic to CD4 T cells (Fig. 2a-c; Table 2). We have shown previously that mitochondrial viability steadily decreases prior to cell death induced by cytopathogenic laboratory isolates of HIV-1.8 ${ }^{8}$ To determine whether mitochondrial viability decreased in CD4 $\mathrm{T}$ cells infected with the 

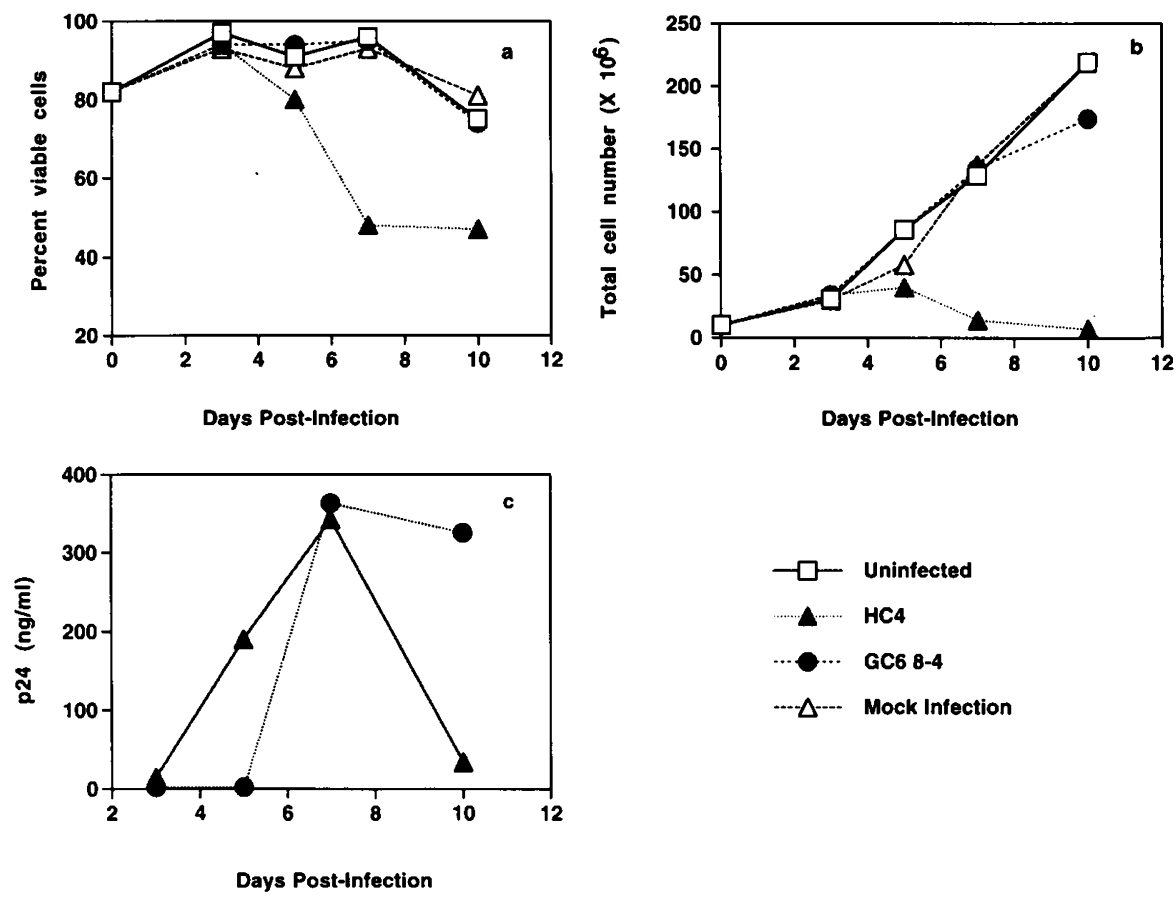

FIG. 2. Viability of CD4 T cells infected with functional, biologically cloned patient HIV-1. CD4 T cells were enriched according to the procedure outlined in Materials and Methods. CD4 T cells were infected with titered biological HIV-1 clones isolated from asymptomatic (patient A) or symptomatic (patient D) individuals, or infected with a pol-defective NL4-3 strain of virus derived from 8E5 cells (mock infection). After the initial exposure to the virus, the culture was carried out in the presence of anti-CD4 monoclonal antibody to inhibit syncytium formation and secondary infections. Single cell death was determined using the trypan blue dye exclusion assay and percent viable cells was calculated. HIV-1 replication in infected CD4 T cell cultures was measured by assaying cell-free culture supernatants for HIV-1 p24gag protein, using an antigen capture ELISA. (a) Percent viable cells in infected CD4 T cells. (b) Total number of viable cells in cultures of CD4 T cells mock infected or infected with biological HIV-1 clones. (c) HIV-1 p24sag protein from infected CD4 T cells. HC4, Cytopathogenic HIV-1 clone from patient D; GC6 8-4, noncytopathogenic HIV-1 clone from patient A.

CP HC4 virus, infected and uninfected cells were stained with rhodamine-123 dye and the histograms were statistically analyzed. The $D / s(n)$ value between the histograms of uninfected cells and HC4-infected cells dramatically increased over the period of day 3 to day 7 postinfection. On day 3 postinfection it was 1.19 , which increased to 6.52 by day 5 , and to 13.04 by day 7 (Table 2). These data demonstrate that the rhodamine123 fluorescence of infected cells was greatly reduced and provide evidence that the number of functionally viable mitochondria was very low in comparison to uninfected cells. In contrast, the levels of viable mitochondria in CD4 $\mathrm{T}$ cells infected with the NCP HIV-1 clone GC6 8-4 were similar to the levels of viable mitochondria in uninfected or mock-infected CD4 T cells (Table 2). The $D / s(n)$ value between the histograms of uninfected cells and GC6 8-4-infected cells was 1.89 on day 3 postinfection, with minimal change to 2.02 on day 5 and to 2.28 on day 7 postinfection (Table 2 ).

\section{DISCUSSION}

In vivo infection with HIV-1 is typically characterized by progressive clinical and immunological deterioration associated with a decrease in CD4 $\mathrm{T}$ cells. The mechanism of CD4 T cell depletion in vivo and its role in HIV-1 pathogenesis and development of AIDS are not well understood. Earlier reports have proposed syncytium formation and high viral burden as

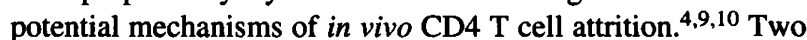
studies indicate that CD4 $\mathrm{T}$ cell depletion is associated with high levels of virus production. ${ }^{11,12}$ These reports suggest that viral load/replication is primarily responsible for HIV-1 pathogenesis. However, we have identified rare, vertically infected individuals who have maintained normal CD4 T cell counts and who have remained asymptomatic in spite of persistently high peripheral blood viremia. One such individual described in this report, patient $A$, has normal CD4 T cell counts $\left(1231 / \mathrm{mm}^{3}\right)$ and has remained asymptomatic for the past 7 years despite high viral load in vivo. The HIV-1 p24 antigen level in serum from patient $\mathrm{A}$ as determined by immune complex dissociation assay was $1773 \mathrm{pg} / \mathrm{ml}$. Viral RNA copies in plasma were $280,000 / \mathrm{ml}$. These individuals provide a unique opportunity to study viral determinants of HIV-1-induced CD4 T cell destruction.

We have previously shown that (1) the syncytium-inducing ability of patient HIV-1 isolates is not always correlated with induction of CD4 T cell death; (2) HIV-1 isolates replicate in MT-2 cells in the absence of syncytium formation; and (3) progressive immune deficiency occurs in vivo in patients who do 
not have SI viral isolates. ${ }^{27}$ In this article we have described a cell culture system to study in vitro cytopathic effects of primary HIV-1 isolates that are independent of syncytium formation and secondary infection. We also observed that viral replication alone does not predict the single cell killing capacity of primary HIV-1 isolates. HIV-1 isolates from an asymptomatic individual with normal CD4 $\mathrm{T}$ cell numbers and a symptomatic individual with $\mathrm{CD} 4 \mathrm{~T}$ cell depletion replicated to equivalent levels of p24 antigen in primary CD4 T cells. However, the isolate from the symptomatic individual induced cell death and the isolate from the asymptomatic individual was noncytopathogenic. It is known that HIV-1 exists in the host as a group of related viruses known as a quasispecies. ${ }^{28}$ This diversity allows the virus a broad spectrum of genotypes that result in multiple phenotypic properties. It follows then that a single viral isolate may contain a number of variants that differ in their ability to form syncytia, and that differ in cell tropism, replication kinetics, as well as cytopathogenic potential. Interestingly, func- tionally active biological clones isolated from the noncytopathogenic isolate did not induce cell death in our culture system in spite of levels of viral replication equivalent to those seen with biological clones of a cytopathogenic isolate that induced cell death.

The mechanism(s) of HIV-1-induced cell death are not well understood. Our hypothesis is that intracellular events after viral entry in combination with cellular/viral factors intricately involved in the viral life cycle may play a major role in the cytopathic effects of HIV-1. We have previously shown that cytopathogenic HIV-1 laboratory isolates decrease mitochondrial viability in infected CD4 T cells and cause cell death. ${ }^{8}$ We have also demonstrated that concomitant to the decrease in mitochondrial viability, HIV-1 RNA localized within mitochondria. ${ }^{8}$ The decrease in mitochondrial viability preceded cell death in cells infected with cytopathogenic HIV-1, suggesting that the loss of mitochondrial viability was the cause and not the effect of cell death. ${ }^{8}$ The levels of viable mitochondria in cells in-

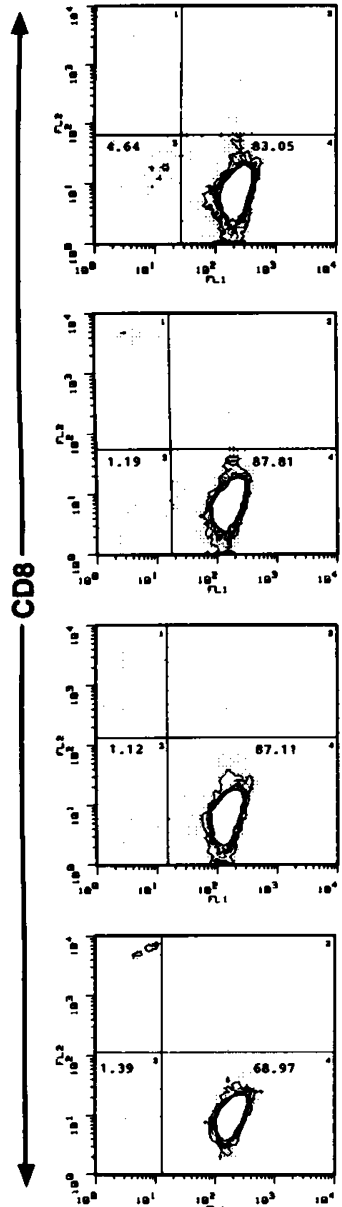

a.
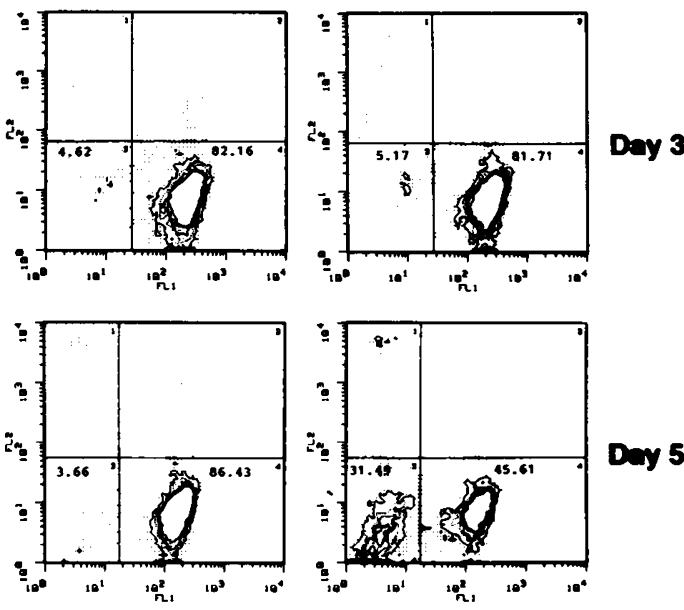

Doy 5
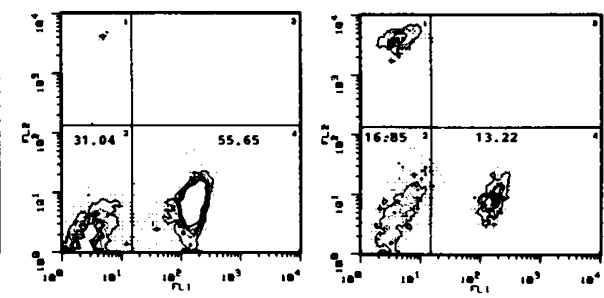

Day 7

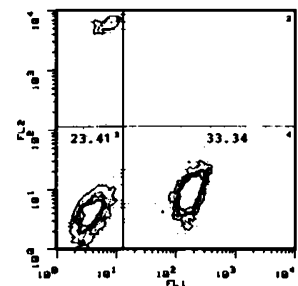

b.

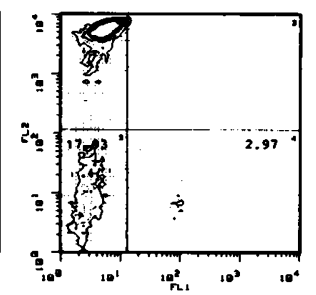

Day 10

CD4

FIG. 3. Determination of percent CD4 and CD8 T cells in CD4 T cell-enriched cultures infected with cytopathogenic or noncytopathogenic HIV-1 biological clones. CD4 T cells were enriched and infected with a cytopathogenic HC4 biological clone, or a noncytopathogenic GC6 8-4 biological clone, as described in the caption to Fig. 2 . The percentage of CD4 ${ }^{+}$and CD8 ${ }^{+} \mathrm{T}$ cells in the infected cultures on days $3,5,7$, and 10 postinfection was determined by FACScan flow cytometer, according to the procedures described in Materials and Methods, and is given in the lower quadrants of the panels. (a) Mock-infected cultures; (b) noncytopathogenic, GC6 8-4 clone-infected cultures; (c) cytopathogenic, HC4 clone-infected cultures. 
fected with noncytopathogenic HIV-1 biological clone GC6 84 were similar to the levels of viable mitochondria in uninfected cells, while in the cells infected with CP HIV-1 biological clone $\mathrm{HC} 4$ there was a dramatic decline in mitochondrial viability, suggesting a possible role for mitochondria in HIV-1 cytopathogenicity. While the results are suggestive of a causal link between mitochondrial viability and cell death more definitive experiments are necessary. The association of HIV-1induced cell death and mitochondrial dysfunction and mitochondrial disintegration is not without precedence. Macho et al. reported their findings on mitochondrial dysfunction in circulating $\mathrm{T}$ lymphocytes of individuals infected with HIV-1. ${ }^{29}$ They observed a correlation between increased disruption of mitochondrial membrane potential in $\mathrm{T}$ cells and disease progression and suggested a potential role for mitochondria in in vivo CD4 T cell loss. These investigators, however, did not determine mitochondrial dysfunction specifically in HIV-1-infected CD4 T cells. HIV-1 is not the only lentivirus associated with mitochondrial dysfunction. In vitro infection of cell lines with feline immunodeficiency virus (FIV) also resulted in a reduction in mitochondrial transmembrane potential prior to cell death. ${ }^{30}$ Taken together, the data support a potential role for mitochondria in virus-induced cell death.

Although the mechanism(s) of HIV-1-induced loss of mitochondrial viability is unclear and the potential role of cellular/viral factors in this process has not been identified, patientderived biological HIV-1 clones and the in vitro culture system described in this article will be useful in future studies to determine the role of mitochondria or other cellular/viral factors in HIV-1 pathogenesis. In addition, molecular and functional analyses of the biological clones to determine the gene(s) responsible for cytopathogenicity will assist in the development of new therapeutic modalities.

\section{ACKNOWLEDGMENTS}

We thank Dr. Greg Viglianti for his critical review of this manuscript, and S. Mohan, K. S. Byron, and R. Huelsman for their technical assistance. This work was supported in part by NIH grants (HL-42257 and AI-32907) and by a grant from the Pediatrics AIDS Foundation, AMFAR (M.S.)

\section{REFERENCES}

1. Fauci AS: The human immunodeficiency virus: Infectivity and mechanisms of pathogenesis. Science 1988;239:617-622.

2. Fauci AS: Multifactorial nature of HIV disease: Implications for therapy. Science 1993;262:1011-1018.

3. Somasundaran $M$ and Robinson HL: Unexpectedly high levels of HIV-1 RNA and protein synthesis in a cytocidal infection. Science 1988;242:1554-1557.

4. Sodroski J, Goh WC, Rosen C, Dayton A, Terwilliger E, and Haseltine WA: Role of the HTLV-III/LAV envelope in syncytium formation and cytopathogenicity. Nature (London) 1986;322: 470-474.

5. Koga Y, Sasaki M, Yoshida H, Oh-Tsu M, Kimura G, and Nomoto $\mathrm{K}$ : Disturbance of nuclear transport of proteins in CD4 cells expressing gp160 of human immunodeficiency virus. J Virol 1991;65:5609-5612.
6. Pauza CD, Galinde JE, and Richman DD: Reinfection results in accumulation of unintegrated viral DNA in cytopathic and persistent human immunodeficiency virus type 1 infection of CEM cells. J Exp Med 1990;172:1035-1042.

7. Laurent-Crawford AG, Krust B, Muller S, Rivire Y, Rey-Cullie MA, Bechet JM, Montagnier L, and Hovanessian AG: The cytopathic effect of HIV is associated with apoptosis. Virology 1991;189:695-714.

8. Somasundaran M, Zapp ML, Beattie LK, Pang L, Byron KS, Bassell GJ, Sullivan JL, and Singer RH: Localization of HIV RNA in mitochondria of infected cells: Potential role in cytopathogenicity. J Cell Biol 1994;126:1353-1360.

9. Ho DD, Moudgil T, and Alam M: Quantitation of human immunodeficiency virus type 1 in the blood of infected persons. N Engl J Med 1989;321:1621-1625.

10. Coombs RW, Collier AC, Allain JP, Nikora B, Leuther M, Gjerset GF, and Corey L: Plasma viremia in human immunodeficiency virus infection. N Engl J Med 1989;321:1626-1631.

11. Ho DD, Neumann AU, Perelson AS, Chen W, Leonard JM, and Markowitz M: Rapid turnover of plasma virions and CD4 lymphocytes in HIV-1 infection. Nature (London) 1995;373:123-126.

12. Wei X, Ghosh SK, Taylor ME, Johnson VA, Emini EA, Deutsch P, Lifson JD, Bonhoeffer S, Nowak MA, Hahn BA, Saag MS, and Shaw GM: Viral dynamics in human immunodeficiency virus type 1 infection. Nature (London) 1995;373:117-122.

13. Hollinger FB, Bremer JW, Myers LE, Gold JWM, and the NIH/NIAID/DAIDS/ACTG Virology Laboratories: Standardization of sensitive human immunodeficiency virus: Coculture procedures and establishment of a multicenter quality assurance program for the AIDS Clinical Trials Group. J Clin Microbiol 1992;30:1787-1794.

14. Japour AJ, Mayers DL, Johnson VA, Kuritzkes DR, Beckett L, Arduino A, Lane I, Black R, Reichelderter PS, D'Aquila RT, Crumpacker CS, and the RV-43 Study Group and the AIDS Clinical Trials Group Virology Committee Resistance Working Group: A standardized peripheral mononuclear cell culture assay for the determination of drug susceptibilities of clinical human immunodeficiency virus type 1 isolates. Antimicrob Agents Chemother 1993;37:1095-1101.

15. Connor RI, Notermans DW, Mohri H, Cao Y, and Ho DD: Biological cloning of functionally diverse quasispecies of HIV-1. AIDS Res Hum Retroviruses 1993;9:541-546.

16. Goudsmit J, Geelen J, Keulen W, Notermans D, Kuiken C, Ramautarsing C, Smit L, Koole L, van Genderen M, Buck H, Sniski $\mathrm{J}$, and Krone W: Characterization of the African HIV-1 isolate CLB-4 (RUT) by partial sequence analysis and virus neutralization with peptide antibody and antisense phosphate-methylated DNA. AIDS 1990;6:559-564.

17. Ratner L, Haseltine W, Patarca R, Livak KJ, Starcich B, Josephs SF, Doran JA, Rafalski ER, Whitehorn EA, Baumeister K, Ivanoff L, Petteway SR, Pearson ML, Lautenberger JA, Papas TS, Ghrayeb J, Chang NT, Gallo RC, and Wong-Staal F: Complete nucleotide sequence of the AIDS virus, HTLV-III. Nature (London) 1985;313:277-283.

18. LaRosa GJ, Davide JP, Weinhold K, Waterbury JA, Profy AT, Lewis JA, Langlois AJ, Dreesman GR, Boswell RN, Shadduck P, Holley LH, Karplus M, Bolognesi DP, Matthew TJ, Emini EA, and Putney SD: Conserved sequence and structural elements in the HIV-1 principal neutralizing determinant. Science 1990;249:932-935.

19. Koot M, Vos AHV, Keet RPM, de Goede RY, Dercksen MW, Terpstra FG, Coutinho RA, Miedema F, and Termsette M: HIV-1 biological phenotype in long-term infected individuals evaluated with an MT-2 cocultivation assay. AIDS 1991;6:49-54.

20. Hollinger FB (Ed.): HIV syncytium-inducing (MT-2) assay. In: ACTG Virology Manual for HIV Laboratories (version 2.1). Division of AIDS, NIAID, Bethesda, Maryland, 1993, pp. SLA-1-3.

21. Folks TM, Powell D, Lightefoot M, Koenig S, Fauci AS, Benn S, 
Rabson A, Daugherty D, Gendelman HE, Hoggan MD, Venkatesan $S$, and Martin MA: Biological and biochemical characterization of a cloned Leu-3- cell surviving infection with the acquired immune deficiency syndrome retrovirus. J Exp Med 1986;164:280-290.

22. Somasundaran M and Robinson HL: A major mechanism of human immunodeficiency virus-induced cell killing does not involve cell fusion. J Virol 1987;61:3114-3119.

23. Saiki RK, Gelfand DH, and Stoffel S: Primer directed enzymatic amplification of DNA with a thermostable DNA polymerase. Science 1988;239:487-491.

24. Singer RH, Byron KS, Lawrence JB, and Sullivan JL: Detection of HIV-1 infected cells from patients using nonisotopic in situ hybridization. Blood 1989;74:2295-2301.

25. Chen LB: Mitochondrial membrane potential in living cells. Annu Rev Cell Biol 1988;4:155-181.

26. Young IT: Proof without prejudice: Use of the Kolmogorov-Smirnov test for analysis of histograms from flow systems and other sources. J Histochem Cytochem 1977;25:935-941.

27. Forte SE, Byron KS, Sullivan JL, and Somasundaran M: Non-syncytium inducing HIV-1 isolated from infected individuals replicate in MT-2 cells. AIDS Res Hum Retroviruses 1994;10:1613-1618.
28. Goodenow MT, Huet T, Saurin W, Kwok S, Sninsky J, and WainHobson S: HIV-1 isolates are rapidly evolving quasispecies: Evidence for viral mixtures and preferred nucleotide substitutions. J AIDS 1989;2:344-352.

29. Macho A, Castedo M, Marchetti P, Aguilar JJ, Decaudin D, Zamzami N, Girard PM, Uriel J, and Kroemer G: Mitochondrial dysfunctions in circulating $\mathrm{T}$ lymphocytes from human immunodeficiency virus-1 carriers. Blood 1995;86:2481-2487.

30. Danave IR, Tiffany-Gastiglioni E, Zenger E, Barhoumi R, Burghardt RC, and Collisson EW: Feline immunodeficiency virusdecreases cell-cell communication and mitochondrial membrane potential. J Virol 1994;68:6745-6750.

Address reprint requests to: Mohan Somasundaran Department of Pediatrics Program in Molecular Medicine University of Massachusetts Medical Center 373 Plantation Street Worcester, Massachusetts 01605 